\title{
Brendecke, Arndt, Imperium und Empirie. Funktionen des Wissens in der spanischen Kolonialherrschaft
}

\section{Axelle Chassagnette}

\section{OpenEdition}

\section{Journals}

Édition électronique

URL : http://journals.openedition.org/ifha/6633

DOI : 10.4000/ifha.6633

ISSN : 2198-8943

\section{Éditeur}

IFRA - Institut franco-allemand (sciences historiques et sociales)

Référence électronique

Axelle Chassagnette, «Brendecke, Arndt, Imperium und Empirie. Funktionen des Wissens in der spanischen Kolonialherrschaft », Revue de I'IFHA [En ligne], Date de recension, mis en ligne le 01 janvier 2011, consulté le 22 septembre 2020. URL : http://journals.openedition.org/ifha/6633 ; DOI : https:// doi.org/10.4000/ifha.6633

Ce document a été généré automatiquement le 22 septembre 2020.

(C)IFHA 


\title{
Brendecke, Arndt, Imperium und Empirie. Funktionen des Wissens in der spanischen Kolonialherrschaft
}

\author{
Axelle Chassagnette
}

1 Dans cet ouvrage tiré de sa thèse d'habilitation, A.B. étudie les relations entre savoir et pouvoir dans l'espace colonial espagnol de la première modernité, et s'interroge sur le rôle qu'ont pu jouer ces relations dans la construction de l'État moderne. Les voyages de découverte, les conquêtes militaires puis l'exploitation économique de territoires du nouveau monde entre la fin du XVe siècle et les premières décennies du XVIe siècle ont permis à la monarchie espagnole d'étendre sa souveraineté bien au-delà de l'Europe, pour construire, selon une formule largement utilisée par les historiens, un « empire sur lequel le soleil ne se couche jamais ». Les difficultés de gouvernement et d'administration qu'a pu poser un empire de cette étendue, les ambitions de la christianisation, les conséquences savantes, épistémologiques, morales et philosophiques des contacts entre Européens et sociétés indigènes ont fait l'objet de nombreux travaux tant en Allemagne qu'en France, menés par les américanistes spécialistes - notamment - de l'histoire des savoirs et des ordres religieux.

2 L'originalité du travail d'A.B. ne tient pas tant à la nature des sources ou des faits historiques qu'il utilise - souvent déjà bien connus - qu'à la problématique et à l'approche théorique qu'il met en œuvre, ainsi qu'à l'œuvre de synthèse que constitue son ouvrage. Son ambition est en effet d'analyser, pour l'administration d'un pouvoir central, la complexité, les ambiguïtés et les enjeux de la maîtrise d'un savoir portant sur des terres lointaines. Il ne s'agit donc pas au premier chef d'étudier les contenus de connaissance (même si l'auteur les décrit quelquefois avec une relative précision) mais de mettre en lumière, dans une perspective théorique d'histoire de la communication actuellement très prisée des modernistes allemands, les stratégies politiques d'assimilation, de contrôle et d'usage de cette connaissance.

3 L'ouvrage comprend neuf chapitres. A.B. s'interroge dans un premier temps sur la théorisation et la justification d'un savoir exhaustif portant sur l'histoire et les 
caractéristiques de l'empire dans son ensemble (à la fois européen et ultramarin), ainsi que sur les instances et les moyens administratifs qui permettent l'établissement et l'exercice d'un pouvoir à distance. Des efforts intensifs et systématiques d'administration sont précocement développés par le pouvoir espagnol et montrent que la mise en place des instances de contrôle relève avant tout d'une volonté de justice de la part du souverain qui dispense punitions, disgrâces et récompenses. Elle relève également d'une volonté de systématiser les pratiques de navigation afin d'assurer la sécurité et la régularité des échanges entre péninsule ibérique et Amérique : c'est ce que montre fort bien l'analyse du développement d'un Padrón Real (une carte en principe utilisée par l'ensemble des marins au service de la couronne espagnole, et validée par le pouvoir central) ainsi que l'activité théorique et savante de la Casa de la Contratación. L'étude centrale du système de la souveraineté coloniale et des relations entre administration ibérique et institutions locales américaines permet à l'auteur de démontrer que le but de la recherche active d'informations sur les colonies n'était pas tant d'établir un portrait complet du nouveau continent que de maintenir sous contrôle, malgré la distance, les acteurs et instances de l'administration coloniale et de s'assurer de leur loyauté. Chaque responsable local pouvait ainsi être perçu successivement par l'administration centrale comme un acteur ou un informateur, observateur de la politique coloniale. Plusieurs chapitres traitent de la réforme du Conseil des Indes par Juan de Ovando et de ses effets. L'un des aspects de cette réforme est le développement de l'usage de formulaires envoyés aux instances coloniales. Ces formulaires devaient permettre d'informer la couronne espagnole sur l'histoire, l'état naturel, agricole, militaire ou démographique des colonies. Le but d'Ovando était d'obtenir l'établissement d'une description complète d'Amérique par les cosmographes de la monarchie. L'étude d'A.B. montre que cet effort fut constamment ralenti par l'inertie des communications, par les nombreux obstacles rencontrés sur place par les instances coloniales, enfin par l'ampleur de la tâche. L'auteur tente enfin, dans son dernier chapitre, d'évaluer l'usage concret de ces savoirs sur les colonies. L'analyse méticuleuse des sources - en particulier des actes administratifs - montre un recours fréquent aux informations écrites ainsi qu'à celles que transmettaient les membres du Conseil des Indes qui, là encore, pouvaient jouer à la fois le rôle d'experts, d'informateurs, et d'acteurs personnellement intéressés à l'avancement des affaires coloniales.

4 Principalement centré sur le XVIe siècle, l'ouvrage d'A.B. retrace donc le premier siècle des stratégies politiques de développement d'un savoir sur les colonies espagnoles. Il manie avec érudition, précision et pédagogie un large corpus de sources savantes, administratives et juridiques. La maîtrise méthodologique et argumentative dont fait preuve l'auteur permet au lecteur de ne jamais s'égarer dans les étapes de la démonstration. 